It is unclear whether the result in the youngest cohort can be explained by aggressive tumour growth, by too low a sensitivity of the mammographic test, by too short a follow-up, or by chance. The absence of any effect so far in the youngest age-group corresponds with the early results of the age-group 40-49 at entry in the Health Insurance Plan (HIP) trial. 5 years after the HIP screening programme had begun, the number of breast cancer deaths was 19 in the study group and 20 in the control group $(R R=0 \cdot 95) .{ }^{3} 10$ years after the start the RR was $42 / 54(0 \cdot 78)$, and 14 years after the start it was $46 / 61(0 \cdot 75) .{ }^{4}$ Nevertheless the HIP investigators hesitated to accept this finding as evidence of the effectiveness of screening under age 50 .

In Nijmegen a disease stage classification system according to mammographical and/or histopathological tumour size was used. "Advanced stage" means that the axillary lymph nodes were histologically involved or that the lesion consisted of infiltrative carcinoma and was at least $2 \mathrm{~cm}$ in size. In the age-group 35-49 at diagnosis $38 \%$ of 40 screen-detected cases had advanced disease stage, as opposed to 4 out of the 6 cases in women who did not participate in the screening programme. According to these figures a subsequent mortality reduction can be expected in the youngest age-group.

Finally, attention should be paid to the weak effect of screening on breast cancer mortality in the oldest age-group. It is assumed that breast cancer grows rather slowly in this group. 5,6 As a consequence, the lead-time should be very long, and a strong effect could be expected after a longer period of follow-up. The odds ratio for the birth cohort born before 1910 is now only 0.81 . Maybe this $\mathrm{RR}$ estimate is weak because of different underlying mortality risks (independent of any screening effect) in the participating and nonparticipating groups. Maybe differences in patient's delay explain that the effect was less favourable than expected. And maybe selective misclassification of the death certificates is another explanation. Further studies will focus on these potential biases.

$\begin{array}{ll}\text { Departments of Social Medicine, } & \text { A. L. M. VERBEEK } \\ \text { Radiology, and Pathology, } & \text { J. H. C. L. HENDRIKS } \\ \text { University of Nijmegen, } & \text { R. HollaND } \\ 6525 \text { EJ Nijmegen, Netherlands } & \end{array}$

Department of Pathology,

Canisıs-Wilhelmina Hospıtal, Nımegen M. MRAVUNAC

Department of Epidemiology,

University of Limburg

F. STURMANS

1. Verbeek ALM, Hendrıks JHCL, Holland R, Mravunac M, Sturmans F, Day NE. Reduction of breast cancer mortality through mass screening with modern mammography. First results of the Nijmegen Project, 1975-1981. Lancet 1984; i: $1222-24$

2. Breslow NE, Day NE. The analysis of case-control studies. In: Davis W, ed. Statistical methods in cancer research. Lyon: IARC Scientific Publications, 1980: 32.

3. Shapıro S, Strax $\mathrm{Ph}$, Venet $\mathrm{L}$. Periodic breast cancer screening in reducing mortality from breast cancer. YAMA 1971; 215: 1777-85.

4. Shapiro S, Venet W, Strax Ph, Venet $L$, Roeser $R$ Ten-to fourteen-year effect of screening on breast cancer mortality. $\mathcal{F}$ Natl Cancer Inst 1982; 69: 349-55.

5. Fourner D von, Weber E, Hoeffen W, Bauer $M$, Kublı F, Barth V. Growth rate of 147 mammary carcinomas. Cancer 1980; 45: 2198-207.

6 Meyer JS, McDivitt RW, Stone KR, Prey MU, Bauer WC. Practical breast carcinoma cell kinetics: Review and update. Breast Cancer Res Treat 1984; 4: 79-88.

\section{LIFETIME PASSIVE SMOKING AND CANCER RISK}

SiR,--Dr Sandler and colleagues (Feb 8, p 312), in a preliminary report, describe the relative cancer risk for persons living in households with $0,1,2$, and 3 or more members who smoke. The risk increased, both for active and for non-smokers, with the number of household members who smoked, and Sandler et al suggest that exposure to ambient smoke in the household might be responsible.

In table I they normalise the odds ratio for cancer risk to unity for households with no (other) smokers and disregard exposure to cigarette smoke outside the home. Calculating to two decimal places, the odds ratios for households with 1 (other) smoking member are 1.42 for active smokers and 1.45 for non-smokers; for households with 2 (other) smokers the corresponding ratios are $2 \cdot 25$ and $2 \cdot 32$; and for 3 or more, the ratios are $2 \cdot 42$ and $2 \cdot 75$. The risk ratios for active smokers are therefore, within the error limits, the same as for non-smokers; to simplify the argument, I shall treat them as identical.
Suppose the average risk of cancer is $\mathrm{N}$ from all causes unconnected with smoking, A from active smoking, and $\mathrm{P}$ from passive smoking. An active smoker is also a passive smoker of his own ambient cigarette smoke, so the total cancer risk for active smokers in households with no other smoker is $\mathrm{N}+\mathrm{A}+\mathrm{P}$; in households with 1 other smoker the risk is $\mathrm{N}+\mathrm{A}+2 \mathrm{P}$. For nonsmokers, the corresponding risks are $\mathrm{N}$ and $\mathrm{N}+\mathrm{P}$. Because the data of Sandler et al imply that odds ratios (and hence the ratios of relative risks) are virtually identical we require that $(\mathrm{N}+\mathrm{A}+2 \mathrm{P}) /(\mathrm{N}+\mathrm{A}+\mathrm{P})=(\mathrm{N}+\mathrm{P}) / \mathrm{N}$. In other words $\mathrm{A}+\mathrm{P}=0$. This same relation is obtained from relative risks in households with 2 and with 3 or more (other) smokers. A multiplicative model, in which the cancer risk in, for example, an active smoker in a household with no other smokers is of the general form, $\mathrm{N}(1+\mathrm{A}+\mathrm{P})$, where $\mathrm{A}$ and $\mathrm{P}$ are now proportional to the concentration of effective carcinogens in active and passive smokers, respectively, also yields the same equality.

The relation $\mathrm{A}+\mathrm{P}=0$ leaves us with three possible interpretations:

(1) Active and passive smoking are both non-carcinogenic $(\mathrm{A}=\mathrm{P}=0)$. (2) Active smoking is carcinogenic and passive smoking is prophylactic $(A=-P)$. (3) Active smoking is prophylactic and passive smoking is carcinogenic $(P=-A)$.

The statistical uncertainty in Sandler's table $\mathrm{I}$ is large enough to permit slightly less paradoxical inferences, but let us pursue the unthinkable a little further.

Three randomised controlled intervention trials (the Oslo study, ${ }^{1}$ the Whitehall study ${ }^{2}$ and MRFIT ${ }^{3}$ ) provide a direct epidemiological test of the hypothesis that giving up active smoking reduces the risk of cancer. In the "intervention" (low-smoking) groups in these three trials together there were (including registrations as well as deaths in the Whitehall study $\left.{ }^{2}\right) 149$ cancers in a combined entry population of $7746(1.92 \%)$; while in the relatively high-smoking control groups there were 121 cancers in $7797(1 \cdot 55 \%)$. From the orthodox viewpoint-namely, active smoking causes at least $30 \%$ of all cancers-these findings are as paradoxical as the inferences from Sandler's study. We might just be able to postulate complicated, though implausible, causal models to account for Sandler and colleagues' table 1, or we may put those results on one side because of their preliminary character. It is more difficult to evade the implication of the methodologically reputable randomised trials: active cigarette smoking has little or no net carcinogenic action.

Department of Medical Physics,

University of Leeds,

General Infirmary,

Leeds LSI 3EX

Philip R. J. Burch

1. Hermann I, Velve Byre K, Holme I, Leren P. Effect of diet and smoking intervention on the incidence of coronary heart disease: Report from the Oslo Study Group of a randomised trial in healthy men Lancet 1981; 11: 1303-10.

2. Rose G, Hamilton PJS, Colwell L, Shipley MJ. A randomised controlled trial of ant1smoking advice: 10-year results. F Epldemtol Commun HIth 1982; 36: 102-08.

3 MRFIT Research Group. Multiple risk factor intervention trial; Risk factors changes and mortality results. $f A M A 1982 ; 248: 1465-77$

SIR,-Dr Sandler and colleagues' paper on the cumulative effects of lifetime passive smoking on cancer risk appears seriously flawed. They compared 518 out of a total of 740 cancer patients aged 15-59 from a hospital-based tumour registry, with 518 controls of the same age, sex, and race. 309 controls were friends or acquaintances of the patients and 209 were randomly selected by systematic telephone sampling. Results are presented for $369(70 \%)$ cases and $409(79 \%)$ controls. Apart from death before the subjects could be contacted and refusal, only those persons who had "lived with both natural parents for most of the first ten years of life" were analysed. We are told that they supplied information about the smoking habits of their spouse and parents. Presumably, they also supplied information about their own smoking.

The results are shown in three tables, only one of which differentiates between active and passive smoking, and none of which differentiates between sex, age, and race. The belief that these factors do not matter because they were matched for is unsound. The reader has no idea how differences between those 
initially chosen and those finally analysed could have influenced the results. Moreover, as soon as the groups are stratified by active smokers and never smokers, the matching is broken. Until the results have been presented for non-smokers by age, sex, and race no conclusions can be drawn.

Furthermore the truncated age group (15-59 years) has resulted in an unrepresentative selection of cancer cases. Even so, the distribution by cancer site seems strange: there were $62(17 \%)$ cancers of the cervix uteri but only $19(5 \%)$ cancers of the respiratory tract and $48(13 \%)$ breast cancers. The trend in cancer risk from multiple household exposures to cigarette smoke is least impressive for cancer of the respiratory system, where an effect might be expected to be greatest, and most striking for leukaemia and lymphoma where any biological explanation is, to say the least, obscure. The most extraordinary finding appears to have been the very similar trends in cancer risk with number of household members who smoke irrespective of whether the cases smoke 1 or not. Indeed, Sandler and colleagues' publication on the same material in the American fournal of Epidemiology $(1985 ; 121$ : 37-48) shows that the effect of passive smoking on cancer risk appears to have been greater than the effect of active smoking.

School of Public Health,

University of Michigan

Ann Arbor, Michıgan 48109, USA

IAN HIGGINS

${ }_{\star}^{\star}$ These letters have been shown to Dr Sandler and colleagues, whose reply follows.-ED. L.

SIR,-Professor Burch presents an algebraic rearrangement of our data that suggests that smoking is protective. His approach assumes that childhood and adulthood exposures are interchangeable. As we indicated in our paper, the apparently linear trends in table I simplify a complex set of relationships. Our data illustrate that childhood and adulthood exposures may contribute independently to cancer risk in adulthood, but this does not imply that these two exposures are equivalent. Data we present elsewhere suggest the two risks may, in fact, be different (ref 1 , and unpublished). As shown in the accompanying expansion of table II, the odds ratio associated with passive exposure only as an adult was 1.8 for non-smokers but only $1 \cdot 2$ for active smokers (not equal, as Burch's analysis requires). For childhood exposures, the opposite was true: the odds ratio was 1.9 for smokers and 1.3 for non-smokers. Thus, passive exposure in childhood seems to have its greatest effect among persons later exposed to a carcinogen (their own smoking), while passive exposure in adulthood has its largest effect among persons not actively exposed. In short, our data do not support the simplified biological assumptions Burch requires for his analysis.

Dr Higgins raises concern about possible biases in the study and requests additional data. The information he seeks is provided in a paper he cites. ${ }^{1}$ As explicitly stated in both papers, there was no confounding by the variables mentioned by Higgins. The

OVERALL CANCER RISK FROM HOUSEHOLD EXPOSURE TO CIGARETTE SMOKE IN CHILDHOOD AND ADULTHOOD

\begin{tabular}{|c|c|c|c|c|}
\hline & \multirow[b]{2}{*}{$\begin{array}{c}\text { No } \\
\text { exposure }\end{array}$} & \multicolumn{2}{|c|}{ Age period of exposure } & \multirow[b]{2}{*}{ Both } \\
\hline & & $\begin{array}{l}\text { Childhood } \\
\text { only }^{\star}\end{array}$ & $\begin{array}{l}\text { Adulthood } \\
\text { onlyt }\end{array}$ & \\
\hline \multicolumn{5}{|l|}{ Active smokers } \\
\hline Patients & 22 & 63 & 25 & 92 \\
\hline Controls & 38 & 58 & 37 & 65 \\
\hline Odds ratio & $1 \cdot 0$ & $\underbrace{1 \cdot 99}$ & $1 \cdot 2$ & $2 \cdot 4 \neq, 5$ \\
\hline \multicolumn{5}{|l|}{ Non-smokers } \\
\hline Patients & 32 & 44 & 33 & 53 \\
\hline Controls & 61 & 66 & 35 & 33 \\
\hline Odds ratio & $1 \cdot 0$ & $1 \cdot 3$ & $1 \cdot 8 \neq$ & $3 \cdot 1 \neq, 5$ \\
\hline
\end{tabular}

*Exposure to smoking mother, father, or other household member during childhood. tExposure to smoking spouse.

$\neq$ Significant differences between risk with specified exposure and no exposure $(p<0 \cdot 05)$ $\{\mathrm{p}=0.051$.

\$Statistically significant linear trend: no exposure, exposure in only one time period, exposure in both time periods $\left(\chi^{2}\right.$ for trend, $\left.p<0 \cdot 01\right)$ "truncated" age group was chosen because a primary aim of our study was to evaluate effects of mothers' smoking. Since few women smoked before 1920 , we studied cases who were younger than age 60 in 1980 . It will be several years before cancer risk associated with mothers' smoking can be evaluated for older persons. The distribution of cancer sites studied resulted from methodologic decisions and hospital referral patterns which were discussed in the papers. Nonetheless this group was not preselected on the basis of any prior hypothesis, and it is not easy to see how inclusion of more cancers that are "unrelated" to cigarette smoking would lead to an inflated overall cancer risk from passive smoking.

Higgins cites our finding of a leukaemia effect as one for which "any biological explanation is, to say the least, obscure". On the contrary, cigarette smoke contains chemicals known to be leukaemogenic, and has been associated with increased leukaemia risk in many, ${ }^{2-5}$ although not all ${ }^{6}$ studies. Some of these studies find an apparent dose-response, especially for non-lymphocytic leukaemias. $2,3,5$ The $40-50 \%$ increase in leukaemia risk among smokers is much smaller than that reported for other sites such as the lung, which may account for the lack of interest in smoking and leukaemia. Experimental and biochemical data from a variety of sources (refs 7 and 8, and discussed in our papers) are also consistent with a possible association between leukaemia risk and exposure to cigarette smoke.

There is one final point. Our study was not designed to compare the effects of active and passive smoking. Our method of choosing friend controls inadvertently matched for active smoking, which erases the possibility of observing an effect due to active smoking. Higgins' comparison of the effects of active and passive smoking is not meaningful in our data.

The questions raised by Burch and Higgins do not persuade us that our study is "seriously flawed". We stress the need for additional studies and strongly urge investigators to consider that the range of possible effects from active and passive exposure to cigarette smoke may be broader than has been thought.

\section{National Institute of}

Environmental Health Sciences,

Research Triangle Park,

North Carolina 27709 , USA

D. P. SANDLER

A. J. WILCOX

R. B. EVERSON

1. Sandler DP, Everson RB, Wilcox AJ. Passive smoking in adulthood and cancer risk. Am 7 Epidemiol 1985; 121: 37-48.

2. Kahn HA. The Dorn study of smoking and mortality among US Veterans: Report on $8 \cdot 5$ years of observatıon. Natl Cancer Inst Monogr 1966; 19: 1-125.

3. Hammond EC, Horn D. Smoking and death rates: Report on forty-four months of follow-up of 187783 men $7 A M A 1985 ; 166: 1294-308$.

4. Willams RR, Horn IW. Association of cancer sites with tobacco and alcoho consumption and socioeconomic status of patients: Interview study from the Third National Cancer Survey. $\mathcal{J}$ Natl Cancer Inst 1977; 58: 525-47.

5. Paffenbarger RS, Wing AL, Hyde RT. Characteristics in youth predictive of adult onset malıgnant lymphomas, melanomas, and leukemias: Brief communicatıon. f Natl Cancer Inst 1978; 60: 89-92.

6 Doll R, Peto R. Mortality in relation to smoking: 20 years observations on male Britısh doctors. Br Med J 1976; i1: 1525-36

7. Yamasaki E, Ames BN. Concentration of mutagens from urine by absorption with the nonpolar resin XAD-2: Cigarette smokers have mutagenic urıne. Proc Natl Acad Sc USA $1977 ; \mathbf{7 4 :} 3555-59$

8. DeMarmı DM. Genotoxicity of tobacco smoke and tobacco smoke condensate. Mutat Res 1983; 114: 59-89.

\section{REDUCED RESPONSE OF URAEMIC BLEEDING TIME TO REPEATED DOSES OF DESMOPRESSIN}

SIR,-Treatment with desmopressin (1-deamino-8-D-arginine vasopressin, DDAVP) shortens prolonged bleeding times in patients with von Willebrand disease, ${ }^{1}$ platelet defects, ${ }^{2}$ and uraemia, $^{3-5}$ and in healthy subjects. ${ }^{2}$ The bleeding time correction by desmopressin has been attributed to the raising of plasma concentrations of high-molecular-weight forms of factor VIII (FVIII) related antigen and von Willebrand factor (vWF) activity. In uraemia FVIII-vWF concentrations are normal to high even before desmopressin; here, the presence of abnormal multimers may explain why normal multimers, provided via desmopressin ${ }^{5}$ or cryoprecipitate $e^{5-7}$ are effective.

Published experience with desmopressin in uraemia is limited to short-term responses. When we gave cryoprecipitate $(30 \mathrm{ml} / \mathrm{kg})$ in 